\title{
Suppression of Multidrug resistance via Inhibition of Heat Shock Factor by Quercetin in MDR Cells
}

\author{
Sun-Hee Kim, ${ }^{1,2}$ Gae-Sun Yeo, ${ }^{1}$ \\ Young-Sun Lim, ${ }^{1}$ Chi-Dug Kang, ${ }^{1}$ \\ Cheol-Min Kim ${ }^{1}$ and Byung-Seon Chung ${ }^{1}$ \\ 1 Department of Biochemistry, College of Medicine, Pusan National University, Pusan \\ 602-739, Korea \\ 2 Corresponding author \\ Accepted 28 May 1998
}

Abbreviations: MDR, multidrug resistance; HSF, heat shock factor; HSE, heat shock element; P-gp, P-glycoprotein; FCS, fetal calf serum; GHE-L, golden hamster embryo lung; VCR, vincristine; VBL, vinblastine; CAT, chloramphenicol acetyltransferase

\begin{abstract}
MDR1 promoter has been shown to contain heat shock elements (HSE), and it has been reported that FM3A/M and P388/M MDR cells show a constitutively activated heat shock factor (HSF), suggesting that HSF might be an important target for reversing the multidrug resistance. Therefore, it was examined whether quercetin, which has been shown to interfere with the formation of the complex between HSE and HSF, and to downregulate the level of HSF1, can sensitize MDR cells against anticancer drugs by inhibition of HSF DNA-binding activity. In this study, quercetin appeared to inhibit the constitutive HSF DNA-binding activity and the sodium arsenite-induced HSF DNA-binding activity in the MDR cells. The basal and sodium arsenite-induced MDRCAT activities were remarkably suppressed by the treatment of quercetin. These results were well consistent with the finding that the treatment of quercetin decreased the expression level of P-gp, MDR1 gene product, in dosedependent manner, and markedly increased the sensitivity of MDR cells to vincristine or vinblastine. These results suggest that quercetin can decrease the expression of P-gp via inhibition of HSF DNAbinding activity, and might be useful as a chemosensitizer in MDR cells.
\end{abstract}

Keywords: multidrug resistance (mdr), heat shock factor (HSF), quercetin

\section{Introduction}

The development of resistance of tumor cells to multiple anticancer drugs is one of the critical problems for successful chemotherapy (Beck, 1990; Roninson, 1992; Ling, 1993; Ling, 1997). This resistance can be due to different factors, including failure of drug uptake or activation, alteration in the level of target enzymes such as dihydrofolate reductase and topoisomerase II, activation of enzymatic systems involved in repair of damage to DNA, enhanced expression of detoxifying enzymes such as glutathione S-transferases, and increased anticancer drug efflux (Vendrik et al., 1992) This last mechanism of resistance appears to be a major one, as suggested by numerous in vitro and clinical studies, and it confers multidrug resistance (MDR) and is usually linked to the overexpression of $\mathrm{P}$-glycoprotein (P-gp), a plasma transmembrane glycoprotein encoded by MDR1 genes and thought to act as an ATP-dependent drug efflux pump (Chen et al., 1990; Pastan and Gottesman, 1991; Gottesman and Pastan, 1993). P-gp gene is normally expressed in human tissues, including liver, kidney, pancreas, and small and large intestine, and P-gp localized at the luminal surface of epithelial cells, suggesting that the pump may have a physiological role in the elimination of xenobiotics or some endogenous metabolites (Thiebaut et al., 1997; Fojo et al., 1987; Chin et al., 1989). However, expression of P-gp in cancer cells is associated with the resistance to several types of antineoplastic drugs, mainly anthracyclines, vinca alkaloids and epipodophyllotoxins (Gottesman and Pastan, 1993).

Although, the mechanism involved in the regulation of MDR1 gene expression are still unclear, the expression of MDR1 gene appears to be controlled by various stimuli such as heat shock, heavy metals, differentiation-inducing agents, chemotherapeutics, hormones, and ultraviolet light (Chin et al., 1990; Miyazaki et al., 1992; Chaudhary and Roninson, 1993; Bates, 1989; Zhao et al., 1993). The MDR1 promoter contains two heat shock elements (HSEs), and there are some evidences that HSEs are required for the response to various stimuli. It has been shown that heat shock or sodium arsenite increases the activity of MDR1 promoter via HSEs, and Raf-dependent signaling pathway controls the transcription of MDR1 gene via a mechanism involving the modulation of heat shock factors (HSF) activity (Miyazak et al., 1992; Kioka et al., 1992; Kim et al., 1996).

We have previously demonstrated that MDR cells such as P388/M and FM3A/M cells showed the constitutive HSF DNA-binding activity and the concurrent increase in hsp70 and hsp90 in the absence of stress (Kim et al., 1997). The 
activation of HSF might be an important transcriptional regulator for inducing MDR1 gene, and the overexpression of hsp70 confers resistance to at least some anticancer drugs (Kim et al., 1996; Kioka et al.,1992; Karlseder et al., 1996). Therefore, modulation of HSF activity might be a useful target for overcoming MDR. Quercetin (3, 3', 4', 5, 7-pentahydroxyflavone), which is one of the most widely distributed flavonoids in nature, has been shown to interfere with the formation of the complex between the cis-acting HSEs in the promoter region of the hsp70 gene and HSF, and to downregulate the level of HSF1 (Hosokawa et al., 1992; Nagai et al., 1995). Thus, quercetin is a good candidate molecule for downregulation of constitutive HSF DNA binding activity and thereby reversing the MDR phenotype in MDR cells. In the present study, it was examined whether quercetin can sensitize MDR cells against anticancer drugs by inhibition of HSF DNA-binding activity.

\section{Materials and Methods}

\section{Materials}

$\mathrm{P} 388 / \mathrm{M}$ and $\mathrm{FM} 3 \mathrm{~A} / \mathrm{M}$ cells are MDR sublines isolated from parental P388 mouse leukemia cell line and FM3A mouse mammary carcinoma cell line, respectively. The MDR sublines have a classical MDR phenotype with overexpression of the MDR1 gene as described previously (Kim et al., 1993). Both the parental cells and MDR sublines were cultured in RPMI (GIBCO BRL, Gaithersburg, MO) supplemented with $10 \%$ fetal calf serum (FCS). Golden hamster embryo lung (GHE-L) cell line (kindly provided by Dr. Yamaguchi Nobuo, Institute of Medical Science, University of Tokyo) was cultured in Dulbecco's modified Eagle's medium (GIBCO BRL, Gaithersburg, MO) supplemented with $10 \%$ FCS. The plasmid p432-CAT, which contains a $1 \mathrm{~kb}$ genomic fragment containing $0.43 \mathrm{~kb}$ region upstream from the major transcription initiation site of human MDR1 gene linked to bacterial chloramphenicol acetyltransferase (CAT) gene, was obtained from the Japanese Foundation of Cancer Research (Ogura et al., 1991). Vincristine, vinblastine, sodium arsenite, 3-(4,5dimethylthiazol-2-yl)-2,5-diphenyl-tetrazolium bromide (MTT), and quercetin were obtained from Sigma (St. Louis, MO). Silica gel plates $\left(60 \mathrm{~F}_{254}\right)$ were purchased from Merck (Damstadt, Germany). [ $\left.{ }^{14} \mathrm{C}\right]-$ Chloramphenicol was purchased from Amersham (Arlington Heights. IL).

\section{Growth inhibition assay and CAT assay}

The effect of anticancer drugs on cellular growth in the absence or presence of quercetin was determined using MTT assay as described previously (Mosmann, 1983) The cells were preincubated for $48 \mathrm{~h}$ with $20 \mu \mathrm{M}$ quercetin in 96-well plates. Medium was replaced and various concentrations of vincristine or vinblastine were added. After 48h incubation, MTT was added to each well and plates were incubated in the dark room for $4 \mathrm{~h}$. The waterinsoluble MTT-formazan crystals were dissolved in dimethyl sulfoxide, and reduction of MTT was determined at 570 nm using ELISA reader (Bio-Tek Instruments).

To test the effect of quercetin on sodium arseniteinduced MDR1 promoter activity, GHE-L cells were transfected with $10 \mu \mathrm{g}$ of p432-MDRCAT according to the calcium phosphate method (Kim et al., 1993). After $6 \mathrm{~h}$ transfection, cells were subjected to dimethyl sulfoxide shock for $3 \mathrm{~min}$, followed by incubation for additional 40 h. Indicated concentrations of sodium arsenite and/or quercetin then were added to culture medium for the transfected cells, and CAT assay was carried out $8 \mathrm{~h}$ later. CAT enzymatic activity in the transfected cells was determined by thin layer chromatography as previously described (Kim et al., 1997).

\section{Western blot analysis}

The cells were solubilized in $1 \times$ SDS sample buffer (62.5 mM Tris- $\mathrm{HCl}, \mathrm{pH} 6.8,2 \%$ SDS, 10\% glycerol, 5\% $\beta$-mercaptoethanol, $0.01 \%$ bromophenol blue) and boiled for $4 \mathrm{~min}$. Proteins were electrophoresed in $7.5 \%$ poly-acrylamide gel, and transferred to nitrocellulose membrane (Hybond ECL, Amersham Corp., Arlington Heights, IL). The membrane was blocked with $5 \%$ nonfat milk, and probed with mouse monoclonal antibody against P-gp (Oncogene Science, Manhasset, NY). Immunoreactive protein was detected using an enhanced chemilumine-scence method (ECL; Amersham Corp.).

\section{Electrophoretic mobility shift assay}

For the electrophoretic mobility shift assay, nuclear extracts from cells were prepared as described previously (Kim et al., 1997). Cells $\left(2 \times 10^{6}\right)$ were harvested and washed with cold phosphate buffered saline and resus-pended in $50 \mathrm{ml}$ of lysis buffer $(10 \mathrm{mM}$ HEPES, pH 7.9, $1.5 \mathrm{mM} \mathrm{MgCl}_{2}, 10 \mathrm{mM} \mathrm{KCl}, 0.5 \mathrm{mM}$ dithiothreitol, $0.5 \mathrm{mM}$ phenylmethylsulphonyl fluoride). The cells were allowed to swell on ice for $10 \mathrm{~min}$, after which the cells were resuspended in $30 \mathrm{ml}$ of lysis buffer containing $0.05 \%$ Nonidet P40. Then the tube was vigorously mixed on a vortex machine 3 times for 10 $\mathrm{sec}$, and the homo-genate was centrifuged at $250 \mathrm{~g}$ for $10 \mathrm{~min}$ to pellet the nuclei. The nuclear pellet was resuspended in $40 \mathrm{ml}$ of ice-cold nuclear extraction buffer (5 mM HEPES, pH 7.9, 26\% (v/v) glycerol, 1.5 $\mathrm{mM} \mathrm{MgCl}$, $0.2 \mathrm{mM}$ EDTA, $0.5 \mathrm{mM}$ dithiothreitol, 0.5 $\mathrm{mM}$ phenylmethylsulphonyl fluoride), incubated on ice for 30 min with intermittent mixing, and centrifuged at $24,000 \mathrm{~g}$ for $20 \mathrm{~min}$ at $4^{\circ} \mathrm{C}$. The nuclear extract was either used immediately or stored at $-70^{\circ} \mathrm{C}$ for later use. 
Binding reactions were performed in $20 \mu \mathrm{l}$ mixture containing $10 \mathrm{mM}$ Tris- $\mathrm{HCl}, \mathrm{pH} 7.5,50 \mathrm{mM} \mathrm{NaCl}, 0.5$ $\mathrm{mM}$ EDTA, $1 \mathrm{mM}$ DTT, $2 \mu \mathrm{g}$ poly (dl-dC), and $10 \mu \mathrm{g}$ of each cell extract. This mixture was incubated for $10 \mathrm{~min}$ at room temperature, and then $0.5 \mathrm{ng}$ of a ${ }^{32} \mathrm{P}$-labeled oligonucleotide including HSE derived from the human MDR1 promoter (Xbal-Xhol fragment) was added, and incubation continued for an additional $20 \mathrm{~min}$. After incubation, the reaction mixtures were loaded on $4 \%$ polyacrylamide gels and run in $0.5 \times$ TBE $(44.5 \mathrm{mM}$ Trisborate, $\mathrm{pH} 8.0,1 \mathrm{mM}$ EDTA) at $100 \mathrm{~V}$. Gels were fixed, dried and exposed to $X$-ray film with an intensifying screen overnight at $-70^{\circ} \mathrm{C}$.

\section{Results}

\section{Effect of quercetin on constitutive and sodium arsenite-induced HSF DNA-binding activity in MDR cells}

Since FM3A/M and P388/M MDR cells showed a constitutive HSF DNA-binding activity under the non-stressed condition (Kim et al., 1997) and quercetin has been shown to interfere with the formation of the complex between the HSE and HSF, and to downregulate the level of HSF1 (Hosokawa et al., 1992; Nagai et al., 1995). It was examined whether the constitutive HSF activity in MDR cells could be downregulated by quercetin. When the MDR cells were treated with the indicated concentrations of quercetin, which did not inhibit cell growth, HSF DNA-binding activity was inhibited in a dose-dependent manner in both MDR cells (Figure 1A). These results demonstrated that the constitutively increased HSF DNA-binding activity in MDR cells could be restored by

A)

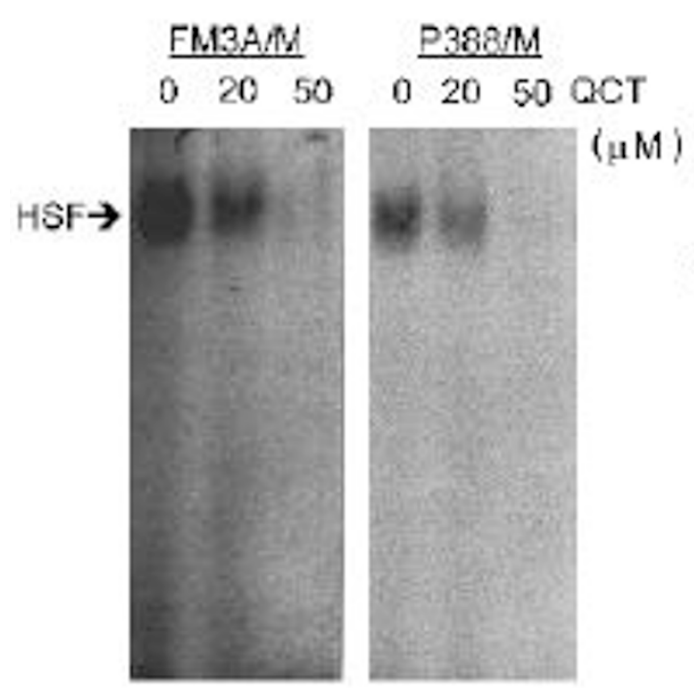

the treatment of quercetin.

It has been previously reported that the transcriptional activation after exposure to arsenite depends on two HSEs in MDR1 promoter (Kim et al., 1996). Therefore, the effect of quercetin on sodium arsenite-induced HSF DNA-binding activity was studied using MDR cells. HSF DNA-binding activity was activated by the treatment of sodium arsenite or was inhibited by the treatment of quercetin, and sodium arsenite-induced HSF DNA-binding activity was inhibited by the treatment of quercetin in both MDR cells (Figure 1B). Pretreatment with quercetin also prevented the ability of sodium arsenite to induce HSF DNA-binding in FM3A/M cells (Figure 1C). These results indicated that quercetin inhibit the induced HSF activity as well as the constitutive HSF activity.

\section{Effect of quercetin on the expression of MDR1 gene in MDR cells}

Because quercetin could inhibit the HSF DNA binding activity in MDR cells, it was asked whether the quercetin can suppress the transcription of MDR1 gene via a mechanism involving the activation of HSF. In this

Figure 1. (A) Effect of quercetin on HSF DNA-binding activity in MDR cell. FM3A/M or P388/M cells were treated with the indicated doses of quercetin (QCT) for $6 \mathrm{~h}$. (B) Effect of quercetin on sodium arsenite-induced HSF DNA-binding activity in MDR cells. FM3A/M or P388/M cells were treated with the indicated doses of sodium arsenite (SA) and/or quercetin (QCT) for $6 \mathrm{~h}$. (C) Effect of the pretreated quercetin on sodium arseniteinduced HSF DNA-binding activity in MDR cells. FM3A/M cells were pretreated with 30 $\mathrm{mM}$ quercetin for $6 \mathrm{~h}$, medium was replaced and cells were then treated with $100 \mathrm{mM}$ sodium arsenite for $3 \mathrm{~h}$. Gel mobility-shift analysis of HSF DNA-binding activity was done using a ${ }^{32} \mathrm{P}$-labeled oligonucleotide including HSE derived from the human MDR1 promoter (Xbal-Xhol fragment) with the nuclear extracts from each cell.

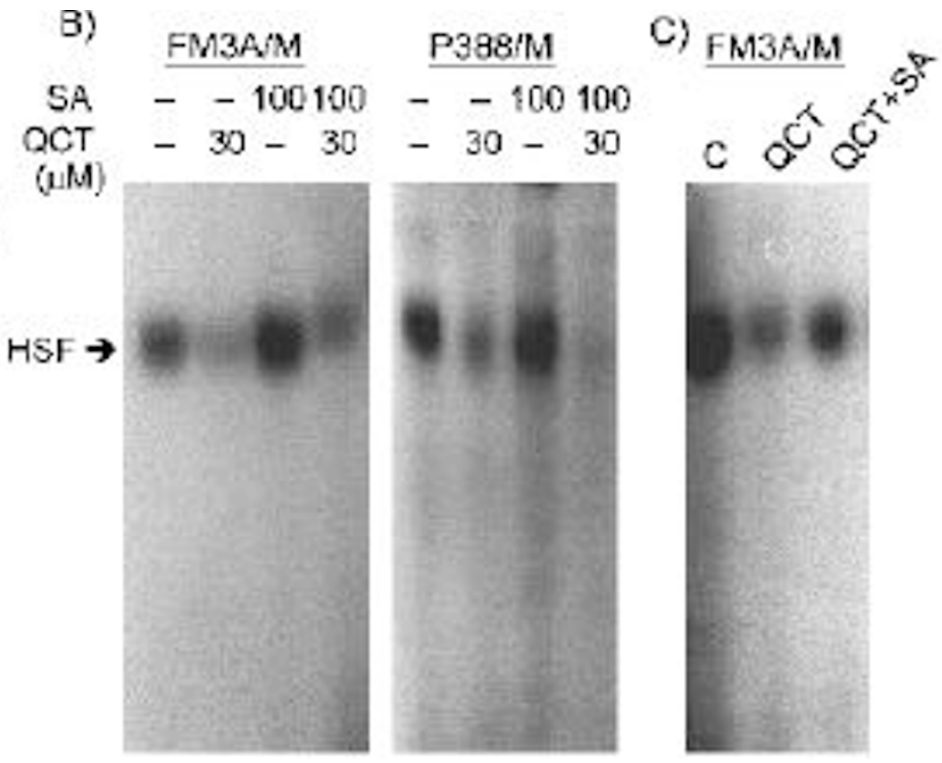


A)

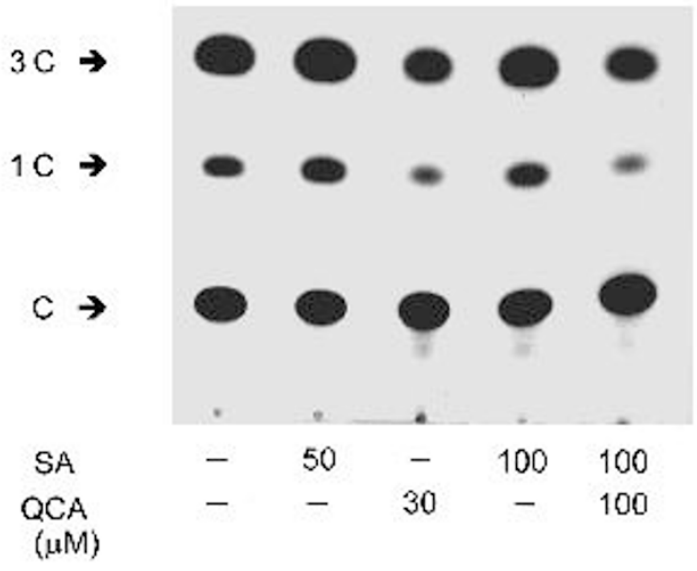

B) 20 50 100 $\mathrm{QCT}(\mu \mathrm{M})$ p170

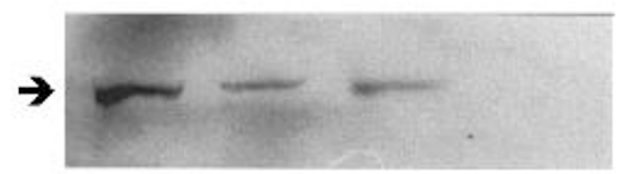

Figure 2. (A) Effect of quercetin on sodium arsenite-induced MDRCAT activity in GHE-L cells. The cells were transiently transfected with $10 \mu \mathrm{g}$ of p432-CAT. After $24 \mathrm{~h}$ of transfection, the cells were treated with the indicated doses of sodium arsenite (SA) and/or quercetin (QCT) for $6 \mathrm{~h}$. The cells were harvested, and aliquots of cell extracts were used to assay for CAT. 3AC, 3acetyl chloramphenicol; 1AC, 1-acetyl chloramphenicol; C, Chloramphenicol. (B) Effect of quercetin on p170 synthesis in MDR cells. The cells were treated with the indicated doses of quercetin for $6 \mathrm{~h}$, and then whole cell lysates were electrophoresed on 7.5\% SDS-polyacrylamide gels and immunoblotted with anti-P-gp (p170) antibody.

Table 1. Effect of quercetin on in vitro sensitivities to anticancer drugs of MDR cells.

\begin{tabular}{ccccc}
\hline \multirow{2}{*}{ Cells } & Drug & \multicolumn{2}{c}{$\mathrm{IC}_{50}(\mathrm{nM})$} & \\
\cline { 3 - 4 } & & QCT free & $\begin{array}{r}+20 \mu \mathrm{M} \text { QCT } \\
\text { pretreatment }\end{array}$ & $\begin{array}{c}\text { Fold } \\
\text { Enhancement }\end{array}$ \\
\hline \multirow{2}{*}{ FM3A/M } & VCR & 350 & 100 & 3.5 \\
& VBL & 660 & 205 & 3.2 \\
\hline \multirow{2}{*}{ P388/M } & VCR & 330 & 110 & 3.0 \\
& VBL & 850 & 360 & 2.4 \\
\hline
\end{tabular}

Cells were treated with anticancer drugs for $48 \mathrm{~h}$ after pretreatment of quercetin (QCT) for $48 \mathrm{~h}$.

regard, it was determined whether quercetin inhibit the sodium arsenite-induced MDRCAT activity using GHE-L cells which were transfected transiently with p432-CAT containing various HSF motifs in MDR1 promoter (Figure 2A). The basal and sodium arsenite-induced MDRCAT activities were remarkably suppressed by the treatment of quercetin and this result was followed by the finding that the P-gp ( $p 170$ ) level was markedly decreased in MDR cells by the treatment of quercetin in dose-dependent manner as shown in western blot analysis (Figure 2B). These results suggested that MDR1 gene expression could be down-regulated by quercetin treatment via HSF DNA binding to HSEs in MDR promoter, and P-gp level in MDR cells could be restored by the treatment of quercetin.

\section{Effect of quercetin on sensitivity to anticancer drugs of MDR cells}

In order to determine whether quercetin can suppress the multidrug resistance, the effect of quercetin on the sensitivity to anticancer drugs of the MDR cells was examined. FM3A/M cells were pretreated for $48 \mathrm{~h}$ with quercetin, medium was replaced and cells were then treated with vincristine or vinblastine. After $48 \mathrm{~h}$ of incubation, the cytotoxicity was assayed. As shown in Table 1, quercetin pretreatment increased approximately 3-fold the sensitivity of MDR cells to both drugs. These results suggest that quercetin might be useful as a chemosensitizer in MDR cells.

\section{Discussion}

There are some evidences that HSF appears to be one of the major regulator of MDR1 gene expression. Several potential HSEs are located in the MDR1 promoter region, 
and heat shock or sodium arsenite increase the activity of MDR1 promoter via HSEs (Miyazaki et al., 1992; Kim et al., 1996; Kioka et al., 1992) . Recently, it has been shown that FM3A/M and P388/M MDR cells isolated in our laboratory have a constitutively activated HSF, and consequently express hsp70, hsp90 and P-gp higher than their parental cells, suggesting that activation of HSF is associated with the increased MDR1 gene expression and HSF could be an useful target for reversing MDR (Kim et al., 1997). Therefore, it is worthwhile to examine whether MDR phenotype could be restored by inhibition of a constitutively active HSF found in MDR cells.

In order to answer this question, MDR cells were treated with quercetin, which is known to inhibit heat shock protein synthesis after heat shock in a human colon carcinoma cell line and Hela cells (Hosokawa et al., 1992) and also interfere with the formation of the complex between the HSE and HSF and downregulate the level of HSF1 (Nagai et al., 1995). In this study, quercetin appeared to inhibit dose-dependently the constitutive HSF DNA-binding activity and the sodium arsenite-induced HSF DNA-binding activity in the MDR cells. These results indicate that quercetin can inhibit the constitutive activity as well as the induced activity of HSF. Because MDR1 gene expression was related with the HSF activity, it could be suppressed by the treatment of quercetin. This suggestion was confirmed with the finding that the basal and sodium arseniteinduced MDRCAT activity was inhibited by the treatment of quercetin, and the increased level of P-gp, MDR1 gene product, was suppressed by the treatment of quercetin in FM3A/M MDR cells.

Since the initial description by Tsuruo et al. (1991) that verapamil was able to downmodulate MDR, many compounds were found to inhibit P-gp-mediated transport and, thus, restore active intracellular levels of anticancer drugs and reverse resistance (Ford and Hait, 1990). Such modulators, also termed chemosensitizers, include calcium channel blockers, calmodulin antagonists, quinolines, immunosuppressive drugs, antibiotics, steroids and hormonal analogs, indol alkaloids and surfactants. Most of these compounds have been proposed to function by competing with anticancer drugs for binding sites on P-gp. In addition, there are some evidences that inhibition of protein kinase A downregulates the expression of MDR1 gene (Kim et al., 1993; Abraham et al., 1990). In the present study, it was found that quercetin increased markedly the sensitivity of MDR cells to MDR-related drugs, presumably due to the inhibition of constitutive HSF activity. Therefore, quercetin, a bioflavonoid widely distributed in plants, would be able to be used as a novel MDR modulator.

In conclusion, these results suggest that quercetin can suppress the MDR1 gene expression via inhibition of the HSF DNA-binding activity, and thereby overcome the MDR phenotype.

\section{Acknowledgement}

This study was supported by the Academic Research Fund (GE 1996) of the Ministry of Education, Republic of Korea.

\section{References}

Abraham, I., Chin, K. V., Gottesman, M. M., Mayo, J. K. and Sampson, K. E. (1990) Transfection of a mutant regulatory subunit gene of cAMP-dependent protein kinase causes increased drug sensitivity and decreased expression of P-glycoprotein. Exp. Cell Res. 189: 133-141

Bates, S. E., Mickley, L. A., Chen, Y. N., Richert, N., Rudick, J., Biedler, J. L. and Fojo, A. T. (1989) Expression of a drug resistance gene in human neuroblastoma cell lines: modulation by retinoic acid-induced differentiation. Mol. Cell Biol. 9: 4337-4344

Beck, W. T. (1990) Mechanisms of multidrug resistance in human tumor cells. The roles of P-glycoprotein, DNA topoisomerase II, and other factors. Cancer Treat. Rev. 17 (Suppl A): $11-20$

Chaudhary, P. M. and Roninson, I. B. (1993) Induction of multidrug resistance in human cells by transient exposure to different chemothera-peutic drugs. J. Natl. Cancer Inst. 85: $632-639$

Chen, C. J., Clark, D., Ueda, K., Pastan, I., Gottesman, M. M. and Roninson, I. B. (1990) Genomic organization of the human multidrug resistance (MDR1) gene and origin of $\mathrm{P}$ glycoproteins. J. Biol. Chem. 265: 506-514.

Chin, J. E., Soffir, R., Noonan, K. E., Choi, K. and Roninson, I. B. (1989) Structure and expression of the human MDR (P-glycoprotein) gene family. Mol. Cell Biol. 9: 38083820

Chin, K. V., Tanaka, S., Darlington, G., Pastan, I. and Gottesman, M. M. (1990) Heat shock and arsenite increase expression of the multidrug resistance (MDR1) gene in human renal carcinoma cells. J. Biol. Chem. 265: 221-226

Fojo, A. T., Ueda, K., Slamon, D. J., Poplack, D. G., Gottesman, M. M. and Pastan, I. (1987) Expression of a multidrug-resistance gene in human tumors and tissues. Proc. Natl. Acad. Sci. USA 84: 265-269

Ford, J. M. and Hait, W. N. (1990) Pharmacology of drugs that alter multidrug resistance in cancer. Pharmacol. Rev. 42: 155-199

Gottesman, M. M. and Pastan, I. (1993) Biochemistry of multidrug resis-tance mediated by the multidrug transporter. Annu. Rev. Biochem. 62: 385-427

Hosokawa, N., Hirayoshi, K., Kudo, H., Takechi, H., Aoike, A., Kawai, K. and Nagata, K. (1992) Inhibition of the activation of heat shock factor in vivo and in vitro by flavonoids. Mol. Cell Biol. 12: 3490-3498

Karlseder, J., Wissing, D., Holzer, G., Orel, L., Sliutz, G., Auer, H., Jaattela, M. and Simon, M. M. (1996) HSP70 overexpression mediates the escape of a doxorubicin-induced G2 cell cycle arrest. Biochem. Biophys. Res. Comm. 220: 153-159

Kim, S. H., Hur, W. Y., Kang, C. D., Lim, Y. S., Kim, D. W. and Chung, B. S. (1997) Involvement of heat shock factor in regulating transcriptional activation of MDR1 gene in multidrug-resistant cells. Cancer Lett. 115: 9-14

Kim, S. H., Lee, S. H., Kwak, N. H., Kang, C. D. and Chung, B. S. (1996) Effect of the activated Raf protein kinase on the human multidrug resistance 1 (MDR1) gene promoter. Cancer Lett. 98: 199-205

Kim, S. H., Park, J. I., Chung, B. S., Kang, C. D. and Hidaka, H. (1993) Inhibition of MDR1 gene expression by H-87, a selective inhibitor of cAMP-dependent protein kinase. Cancer Lett. 74: 37-41

Kioka, N., Yamano, Y., Komano, T. and Ueda, K. (1992) Heat-shock responsive elements in the induction of the multidrug resistance gene (MDR1). FEBS Lett. 301: 37- 
40

Ling, V. (1993) P-glycoprotein-mediated multidrug resistance to cancer chemotherapy. Adv. Oncol. 3-9

Ling, V. (1997) Multidrug resistance: molecular mechanisms and clinical relevance. Cancer Chemother. Pharmacol. 40 Suppl: S3-8.

Mickley, L. A., Bates, S. E., Richert, N. D., Currier, S., Tanaka, S., Foss, F., Rosen, N. and Fojo, A. T. (1989) Modulation of the expression of a multidrug resistance gene (mdr1/P-glycoprotein) by differentiating agents. J. Biol. Chem. 264: 18031-18040

Miyazaki, M., Kohno, K., Uchiumi, T., Tanimura, H., Matsuo, K., Nasu, M. and Kuwano, M. (1992) Activation of human multidrug resistance-1 gene promoter in response to heat shock stress. Biochem. Biophys. Res. Comm. 187: 677-684

Mosmann, T. (1983) Rapid colorimetric assay for cellular growth and survival: application to proliferation and cytotoxicity assays. J. Immunol. Methods 65: 55-63

Nagai, N., Nakai, A. and Nagata, K. (1995) Quercetin suppresses heat shock response by down regulation of HSF1. Biochem. Biophys. Res. Comm. 208: 1099-1105

Ogura, M., Takatori, T., Sugimoto, Y. and Tsuruo, T. (1991) Identification and characterization of three DNA-binding proteins on the promoter of the human MDR1 gene in drug-sensitive and -resistant cells. Jpn. J. Cancer Res. 82: 1151-1159

Pastan, I. and Gottesman, M. M. (1991) Multidrug resistance. Annu. Rev. Med. 42: 277 286
Roninson, I. B. (1992) The role of the MDR1 (P-glycoprotein) gene in multidrug resistance in vitro and in vivo. Biochem. Pharmacol. 43: 95-102

Thiebaut, F., Tsuruo, T., Hamada, H., Gottesman, M. M., Pastan, I. and Willingham, M. C. (1987) Cellular localization of the multidrug-resistance gene product P-glycoprotein in normal human tissues. Proc. Natt. Acad. Sci. USA 84: 7735-7738

Tsuruo, T., lida, H., Tsukagoshi, S. and Sakurai, Y. (1981) Overcoming of vincristine resistance in P388 leukemia in vivoand in vitrothrough enhanced cytotoxicity of vincristine and vinblastine by verapamil. Cancer Res. 41: 1967-1972

Vendrik, C. P., Bergers, J. J., De, J. W. and Steerenberg, P. A. (1992) Resistance to cytostatic drugs at the cellular level. Cancer Chemother. Pharmacol. 29: 413-429

Zhao, J. Y., Ikeguchi, M., Eckersberg, T. and Kuo, M. T. (1993) Modulation of multidrug resistance gene expression by dexamethasone in cultured hepatoma cells. Endocrinology 133: 521-528 